\title{
Subsurface Exploration with the Cone Penetration Testing Truck
}

he U.S. Geological Survey
Cone Penetration Testing
(CPT) truck is a fast and inex-
pensive way to conduct shallow
subsurface exploration. Detailed
data are available immediately,
permitting on-the-fly mapping of
stratigraphy and other subsurface
features. CPT is a useful tool in
geologic-hazard, hydrologic and
environmental studies. This rapid
and cost-effective approach is
particularly advantageous in
urban environments because no
drill spoils are produced. The CPT
truck is available on a reimburs-
able basis to all USGS staff and
cooperators.

Cone penetration testing (CPT) permits rapid exploration of shallow (less than 30 meters) subsurface conditions while minimizing retrieval of subsurface materials, an inconvenient and occasionally expensive byproduct of conventional drilling. This exploration method employs sensors that are pushed into the ground to infer the properties of both soils and pore fluids. Known as direct-push technology, this method can map out the vertical and lateral extent of stratigraphic layers, as well as the distribution of subsurface contaminants. By using standard engineering correlations, the geotechnical properties of stratigraphic layers can also be inferred.

In 1997, the Pacific Gas and Electric Co. (PG\&E), under the PG\&E-U.S. Geological Survey (USGS) Cooperative Research and Development Agreement (CRADA), contributed funds for the CPT truck. The PG\&E-USGS CRADA was created to conduct earthquakehazard investigations and improve earthquake notifications needed for reducing earthquake risks in the San Francisco Bay Region. Since 1998, the USGS CPT truck has provided data for a broad variety of USGS earthquake-hazard, geologic, and hydrologic investigations that require detailed subsurface information.

A CPT sounding is made by pushing a small probe into the ground. Typically, a 3.6centimeter-diameter probe (cone) is pushed into the ground to depths ranging from 15 to 30

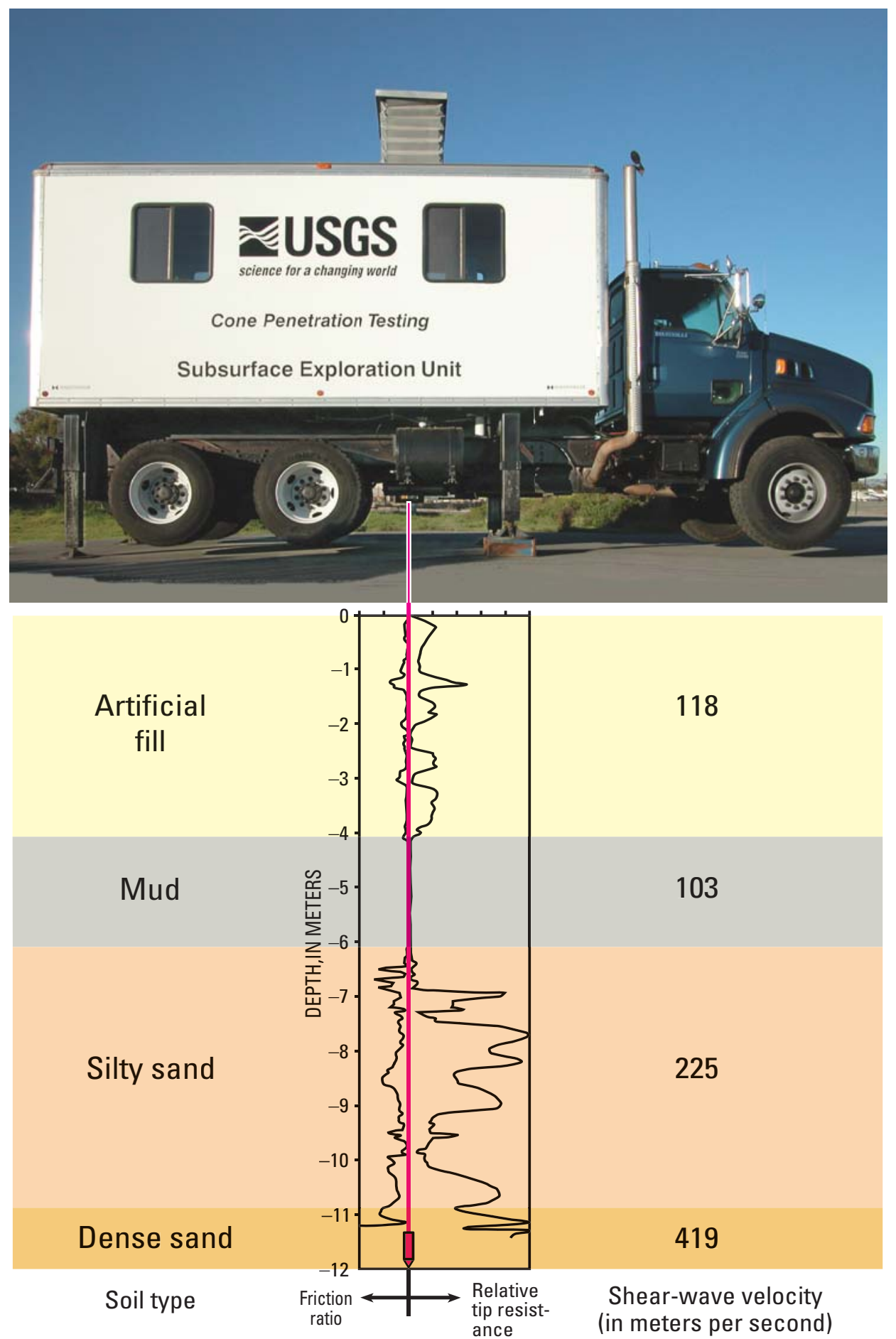

CPT log of friction ratio and relative tip resistance with inferred geologic units and their shear-wave velocities. 
meters. The cone is advanced downward at a constant velocity of 2 centimeters per second, using hydraulic rams that apply the full 23-ton weight of the CPT truck to push the probe rods to depth. In typical CPT soundings, the resistance to penetration is measured. Continuous measurements are made of the resistance to penetration of the tip and the frictional sliding resistance of the sleeve of the cone. The penetration resistance, which is digitized at 5-centimeter depth intervals, permits detailed inferences about stratigraphy and lithology. Soil type is inferred from a chart that compares these two measurements with the known physical properties of various soils.

CPT is a much more rapid and cost effective approach than conventional drilling for shallow subsurface exploration. Typically, four to five 15 - to 30-meter-deep soundings per day can be accomplished, in contrast to one or two per day with conventional drilling and sampling. Soundings also have the great advantage of not producing any drill cuttings, spoils, or fluids. This aspect is particularly advantageous where subsurface contaminants are present or suspected. Data are automatically logged onto a rugged field computer and are ready for immediate viewing and analysis in the field. CPT is a reliable and efficient method for stratigraphic profiling and obtaining soil-engineering parameters for geotechnical design, as well as being widely accepted and encouraged by regulators as an effective environmental-investigation technology.

\section{Various sensors and tools}

Many sensors and tools have been adapted to CPT technology, including electrical-resistivity modules, temperature and volatile-organiccompound (VOC) sensors, ground-water, soil, and discrete-gas samplers, seismometers, inplace vane shear, and video imaging. Though not designed for continuous coring, the CPT truck can collect discrete soil samples with a piston sampler. Either 20- or 60-centimeter-long samples can be retrieved from predetermined depths. Typically, a single sample can be obtained from a depth of 15 meters in less than
30 minutes. All holes, regardless of the type of tooling used, can be sealed by grouting if environmental regulations require backfilling of holes. The USGS uses a pneumatic shear-wave generator capable of producing clean, repeatable shear waves essential for detailed seismicvelocity studies.

\section{Cone Penetration Testing \\ Advantages \\ - Rapid data acquisition \\ - No drilling mess \\ - Immediate data availability \\ - Detailed subsurface information \\ Capabilities}

- Shear-wave-velocity measurement

- Detailed stratigraphic profiling

- Soil sampling

- Pore-fluid-pressure/water-table measurement

- Evaluation of liquefaction potential

- Vane-shear measurement

- Video imagery

- Vertical temperature profiling

- Direct-push sensor installation

- Ground-water sampling

- Monitoring wells

- Conductivity/resistivity measurements

- Ground-penetrating radar

- Discrete-gas sampling

- Regional and site-specific stratigraphy

- Laser-induced fluorescence

- Volatile-organic-compound sensing

\section{Applications}

- Seismic-hazard mapping

- Paleoseismic exploration

- Ground-water-quality studies

- Environmental-contamination studies

- Regional or site-specific three-dimensional mapping of shallow sedimentary deposits

CPT applications are numerous and wide ranging. $\mathrm{CPT}$ measures the thicknesses and

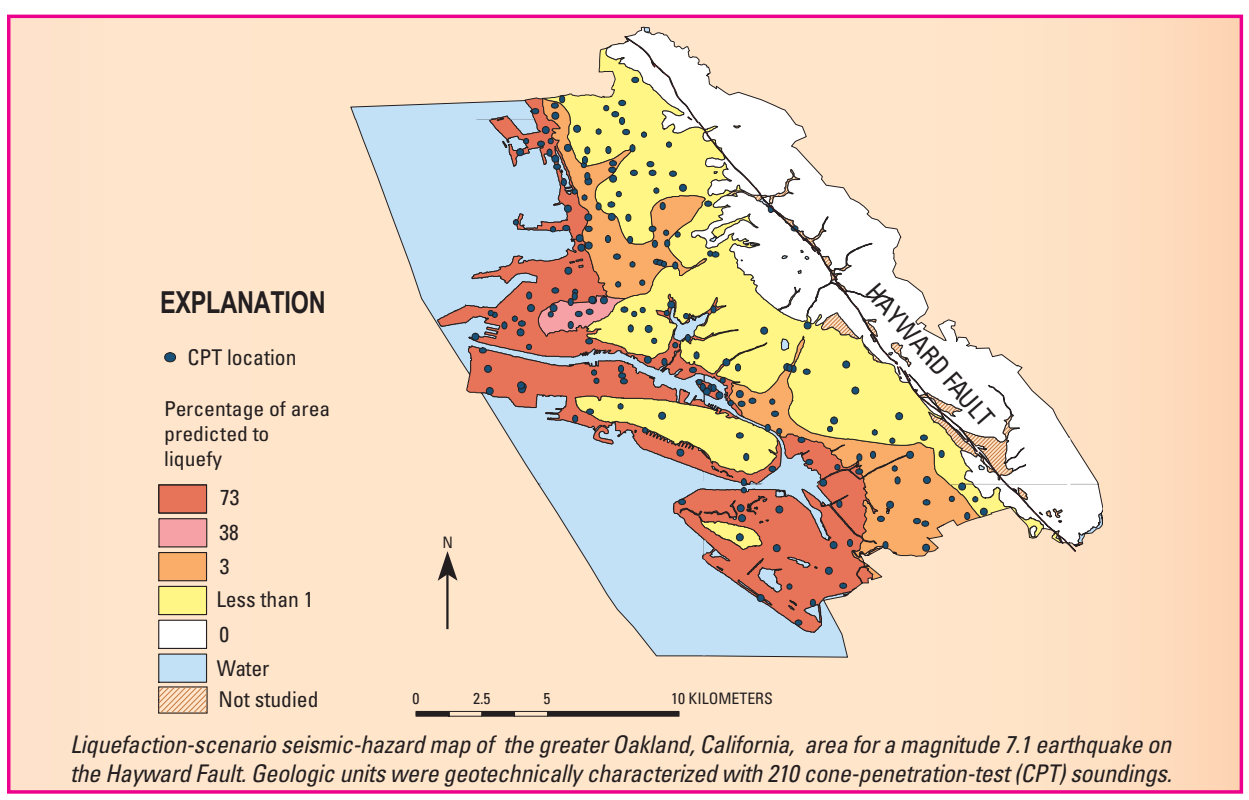

quantifies the physical properties, including shear-wave velocity, of individual geologic units. In combination with maps of surficial geology, this method permits mapping of regional liquefaction hazards and National Earthquake Hazards Reduction Program (NEHRP) site-amplification soil classes used for seismic design. CPT is well suited for mapping the elevations of buried stratigraphic horizons, as well as for reconnaissance of paleoseismic sites, the locations where sedimentary deposits may record evidence of prehistoric earthquakes. For example, CPT can be used to identify areas suitable for trenching of active faults, as well as excluding less desirable trench sites. Closely spaced CPT soundings aligned along a profile provide detailed cross-sectional information, including lateral variation in composition and elevation changes of units. Recent advances in sensor technology have led to the use of CPT to install electricalresistivity-tomography (ERT) electrodes and provide access for ground-penetrating-radartomography (GPRT) antennas. ERT monitors and detects such subsurface processes as contaminant-plume migration. GPRT uses highfrequency radio waves transmitted from one subsurface location and received at a second location. The radar traveltimes image soil-horizon boundaries, buried objects, or faults. CPT is useful to ground-water studies by measuring pore pressure, measuring in-place permeability, and sampling ground water and soil gas. For environmental site investigations, volatileorganic-compound (VOC) sensors in the cone can identify the composition of contaminant plumes and map their distribution and extent. Subsurface video imagery obtained with a cone-mounted camera can measure grain size, using a $20 \times$ magnifying lens and fiber-optic light source.

The U.S. Geological Survey CPT truck is available on a reimbursable basis for all research investigations by USGS staff and cooperators. The CPT truck provides a fast and inexpensive way to conduct shallow subsurface exploration. Detailed data are available immediately, permitting rapid mapping of subsurface features. CPT can expedite geologic-hazard, hydrologic, and environmental studies. This rapid and cost-effective approach is well suited for urban environments because no drill spoils are produced.

\section{Thomas E. Noce and Thomas L. Holzer Edited by \\ George A. Havach Graphic design by \\ Stephen L. Scott}

For more information contact:

Thomas E. Noce

U.S. Geological Survey

345 Middlefield Rd. MS 977

Menlo Park, CA, 94025

Tel: (650) 329-4861

Fax: (650) 329-5163

email: tnoce@usgs.gov

This Fact Sheet and any updates to it are available online at:

http://pubs.usgs.gov/fs/2003/fs028-03/ 